\title{
0 processo de submissão, avaliação e publicação de artigos no Jornal Brasileiro de Patologia e Medicina Laboratorial
}

\author{
The process of submission, evaluation and publication of manuscripts in the Jornal Brasileiro de Patologia e \\ Medicina Laboratorial
}

José Eymard Homem Pittella

Em um editorial publicado recentemente no Jornal Brasileiro de Patologia e Medicina Laboratorial (JBPML), o editor da área de Patologia fez uma compilação das publicações do JBPML dessa área, no período de janeiro de 2009 a abril de 2011, englobando 14 números da revista ${ }^{(1)}$. Dos 174 manuscritos submetidos à publicação, no período em consideração, 61 (35,1\%) foram aceitos e publicados; 75 (43,1\%), recusados; 30 (17,2\%) estavam em fase de análise e 8 (4,6\%) foram aprovados e aguardavam publicação. Esses números demonstram o afluxo de trabalhos submetidos à publicação e a grande responsabilidade em selecionar os manuscritos pelo mérito científico. Embora os leitores e os colaboradores do JBPML estejam certamente familiarizados com o processo de submissão, avaliação e publicação de artigos nas revistas científicas em geral e, em particular, no JBPML, faz-se necessário expor as principais etapas do processo que envolvem uma série de regras e de participantes ${ }^{(6)}$.

A princípio, qualquer autor pode oferecer um artigo científico a ser apreciado para publicação em alguma revista. Ao fazer essa submissão, o autor deve seguir algumas normas na preparação do documento. Essas normas são divulgadas nos exemplares da própria revista e, naquelas que possuem homepage, elas ficam disponíveis continuamente. Para as revistas biomédicas, essas normas foram inicialmente estabelecidas em 1978 por um grupo de editores de revistas médicas reunidos em Vancouver, Canadá, sendo publicadas em 1979. Ao longo dos anos, além das normas de preparação do artigo, o comitê acrescentou outros documentos, denominados declarações separadas, relacionados, principalmente, com os princípios éticos que devem orientar o processo de avaliação e publicação do manuscrito.

Na edição de 2003 dos Requisitos uniformes para manuscritos submetidos a revistas biomédicas, o comitê revisou e reorganizou todos os dados, incorporando ao texto as declarações separadas. Em sua última versão, publicada em $2011^{(4)}$, o documento contém, além das instruções detalhadas de como os autores devem preparar e enviar os manuscritos, considerações éticas sobre condução e relato da pesquisa, como: a) autoria do trabalho; b) papel do editor; c) definição de uma revista com arbitragem pelos pares; d) conflito de interesse entre revisor, autor e editor, por exemplo, envolvendo financiamento da pesquisa ou competição acadêmica que possam influenciar na avaliação do manuscrito; e) direito dos pacientes e dos participantes do estudo à privacidade; f) obrigação de publicar estudos com resultados negativos; g) correção e retratação do autor; h) direito autoral; i) publicação redundante; j) manuscrito contendo interpretações conflitantes dos autores sobre o estudo realizado; k) relação das revistas com os anunciantes e a mídia.

Em relação à ética da pesquisa que originou o manuscrito, os estudos realizados em seres humanos, incluindo órgãos e/ou tecidos isoladamente, bem como prontuários clínicos ou resultados de exames 
clínicos, deverão estar de acordo com a Resolução 196/96 do Conselho Nacional de Saúde(2). Deve ser referido o consentimento informado pelos pacientes ou familiares, não podendo utilizar nomes ou iniciais dos indivíduos ou registros de hospitais, especialmente em material usado para documentação e ilustração. Os autores devem incluir no manuscrito o certificado de aprovação do Comitê de Ética da Instituição na qual foi realizada a pesquisa, em consonância com a Declaração de Helsinque. Como se sabe, essa declaração é um conjunto de princípios éticos que regulamentam a pesquisa em seres humanos. Redigida inicialmente em 1964 pela Associação Médica Mundial, foi revisada posteriormente seis vezes, sendo sua última revisão em 2008. Nos trabalhos experimentais envolvendo animais, devem ser respeitados os princípios éticos de experimentação animal do Colégio Brasileiro de Experimentação Animal e as normas estabelecidas do Guide for the Care and Use of Laboratory Animals de 1996, atualizada em $2011^{(3)}$.

As revistas científicas, com poucas variações, seguem um roteiro bem estabelecido quando recebem um manuscrito a ser apreciado para publicação. Recebido o documento pela equipe editorial, o editor toma a decisão inicial, analisando se o conteúdo do artigo se encontra ou não dentro dos propósitos e dos objetivos da revista. A recusa primária do manuscrito nessa primeira apreciação não significa avaliação negativa do mérito do trabalho, mas apenas que este não se encontra adequado aos objetivos da revista. Caso esteja dentro dos padrões estabelecidos, o artigo será enviado para avaliação. A partir desse momento, o autor correspondente recebe um número de identificação do documento, o qual deve ser indicado em qualquer novo contato com o editor. Nos casos em que os manuscritos são enviados on-line, a forma de envio mais utilizada atualmente, o autor correspondente se cadastra com uma senha, o que permite acompanhar o andamento do processo. Desde novembro de 2008, o JBPML passou a integrar o grupo de revistas que contam com o processo de editoração eletrônica, cobrindo todo o sistema de submissão, recepção, encaminhamento aos revisores, devolução aos autores para correções sugeridas pelos revisores, envio para correções ortográficas e de normas e envio ao tradutor e diagramador ${ }^{(5)}$.

O manuscrito é enviado, pelo menos, para avaliação de dois revisores, escolhidos, na maioria dos casos, pelo editor. Esse processo denomina-se arbitragem por pares (peer review). Os dois revisores escolhidos podem fazer parte do conselho ou da comissão editorial da revista ou, como ocorre mais comumente, não pertencerem à equipe editorial, porém possuem conhecimento específico na área contemplada pelo artigo. Os critérios de escolha dos revisores são: independência em relação aos autores e suas instituições, capacidade para avaliar os aspectos técnicos do trabalho e disponibilidade para analisar o manuscrito dentro do prazo solicitado, em geral, 20 dias. O JBPML dispõe, atualmente, de 240 revisores cadastrados, divididos nas áreas de Patologia Clínica, Patologia e Citopatologia. Cerca de 50\% desses profissionais são provenientes do Estado de São Paulo e a maioria dos revisores restantes, em ordem decrescente, dos Estados de Minas Gerais, Rio de Janeiro, Bahia, Rio Grande do Sul, Paraná e Pernambuco.

Os revisores são solicitados para avaliar o artigo quanto a originalidade, relevância, acurácia, clareza e redação. Além disso, solicita-se que providenciem: a) comentários que poderão ser de utilidade, caso o autor tenha que modificar o documento para nova submissão à mesma revista ou a outra; b) comentários confidenciais ao editor acerca da originalidade e da qualidade do trabalho e de sua conveniência para publicação na revista. Quando há acentuada divergência no parecer dos dois revisores, o manuscrito pode ser enviado para um terceiro revisor como critério de desempate. A decisão final do editor é tomada com base nos comentários dos revisores e na prioridade, ou falta de prioridade, para publicação. A revisão é realizada em regime duplo-cego, ou seja, os autores desconhecem a identidade dos revisores e vice-versa, modelo esse seguido pelo JBPML e por muitas revistas científicas. 
Após essa triagem, o artigo é então: a) aceito para publicação sem revisão (ou no máximo com pequenas alterações ou correções); b) aceito para publicação após revisão pelos autores das sugestões feitas pelos revisores; c) não rejeitado, mas a decisão final é adiada, com encorajamento para os autores tornarem a submeter o artigo após consideração das críticas dos revisores; d) rejeitado. A primeira possibilidade ocorre raramente, enquanto a terceira não dá garantia de eventual aceitação no reenvio do trabalho. Nas situações b e c, ao reenviar o manuscrito revisto, o autor deve anexar uma carta contendo respostas aos comentários dos revisores. Eventualmente, em casos de recusa, o editor pode reconsiderar o texto para nova análise dos revisores, desde que o autor recorra e justifique os motivos que o levaram a considerar que a decisão de rejeição foi equivocada, além de responder aos comentários dos revisores, no caso destes terem sido a causa principal da rejeição do documento. A demora nas respostas dos revisores ao convite para avaliação dos manuscritos ou o retorno destes aos editores, após a avaliação, ou então, demora dos autores em fazer nova submissão depois de efetuada as correções e as modificações sugeridas pelos revisores, contribuem para prolongar o prazo entre a submissão do artigo e sua publicação na revista.

De modo geral, a publicação do manuscrito na revista obedece à ordem cronológica de submissão e/ou aceitação do trabalho. Durante o processo de submissão (especificamente do JBPML) ou após a aceitação para publicação, o autor correspondente receberá do editor os formulários de transferência de declaração de direitos autorais, cedendo para a editora os direitos do artigo que será publicado. Os editores e os revisores não são pagos por sua tarefa. Como recompensa pelo trabalho árduo e voluntário, as revistas os identificam publicando periodicamente seus nomes ou os editores enviam cartas de agradecimento (como é o caso do JBPML).

Além dessa forma usual de um autor submeter um trabalho científico à apreciação para publicação, existe também a publicação a convite, na qual o editor convida especialistas renomados para escrever artigos sob a forma de editorial, atualização e revisão de literatura de um tema específico, educação continuada, notas históricas etc. No JBPML, artigos de revisão são aceitos apenas mediante convite.

Para finalizar, o processo de submissão, avaliação e publicação de artigos no JBPML, no passado e atualmente, tem procurado seguir o mesmo caminho seguido pelas revistas biomédicas científicas nacionais e internacionais. A qualidade desse processo está intimamente ligada ao envolvimento dedicado e contínuo de leitores, autores, revisores, editores e membros da comissão editorial. A melhoria contínua da qualidade do JBPML, a revista oficial de três importantes sociedades médicas, deve continuar a ser objetivo prioritário de todos os associados.

\section{Referências}

1. BARBOSA, A. J. A. Uma visão atual das publicações do JBPML na área de Patologia. J Bras Patol Med Lab, v. 47, n. 5, p. 492-3, 2011.

2. Conselho Nacional de Saúde. Diretrizes e normas regulamentadoras de pesquisas envolvendo seres humanos. Resolução 196/96. Disponível em: <http://www.bioetica.ufrgs.br/res19696.htm>. Acesso em: abr. 2012.

3. Guide for the care and use of laboratory animals. 8 ed. Disponível em: <http://oacu.od.nih.gov/regs/guide/guide.pdf>. Acesso em: abr. 2012.

4. ICMJE. International Committee of Medical Journal Editors. Disponível em: <http://www.icmje.org/urm_main.html>. Acesso em: abr. 2012.

5. Jornal Brasileiro de Patologia e Medicina Laboratorial. Sistema de gestão de publicações. Disponível em: <http://www. jbpml.org.br/sgp/>. Acesso em: abr. 2012.

6. PITTELLA, J. E. Construindo o saber da ciência. Belo Horizonte: Coopmed, 2012. 